\title{
The Role of Cervical Muscles Morphology in the Surgical Treatment of Degenerative Disc Disease: Clinical Correlations Based on Magnetic Resonance Imaging Studies
}

\author{
Ioannis Siasios ${ }^{\mathrm{a}, \mathrm{b}, \mathrm{f}}$, Ethymia Samara ${ }^{\mathrm{c}}$, Aggeliki Fotiadou ${ }^{\mathrm{d}}$, Kalliopi Tsoleka ${ }^{\mathrm{a}}$, \\ Konstantinos Vadikolias ${ }^{\mathrm{d}}$, Michael Mantatzis ${ }^{\mathrm{e}}$, Theodosis Birbilis ${ }^{\mathrm{b}}$
}

\begin{abstract}
Cervical spine musculature still remains a less studied component of the cervical spine anatomical compartments, although it plays a significant role in the mobility of the head and the preservation of cervical spine alignment. The goal of this study was to extract any significant information from the literature regarding the role of cervical spine muscles morphology in the outcome of surgically treated patients for degenerative disc disease (DDD) based on preoperative magnetic resonance imaging (MRI) studies. Eleven clinical case series were found, from which four were prospective and seven were retrospective. Six studies were concentrated on anterior approaches and five studies on posterior approaches in the cervical spine. In posterior approaches aiming at the preservation of muscles attachments and overall less surgical manipulations, results on cervical lordosis, axial pain and patient's functionality were found superior to traditional laminectomies. The study of cross-sectional areas (CSAs) of deep paraspinal muscles in the cervical spine could add significant information for the spine surgeon such as the prediction of adjacent level disease (ALD), fusion failure, axial pain persistence, postoperative cervical alignment and patient's postoperative functionality. It seems that MRI studies focusing on muscle layers of the cervical spine could add significant information for the spinal surgeon regarding the final surgical outcome in terms of pain and function expres-
\end{abstract}

Manuscript submitted June 29, 2021, accepted July 16, 2021

Published online July 28, 2021

aDepartment of Neurosurgery, General Hospital of Papageorgiou, Thessaloniki, Greece

${ }^{b}$ Department of Neurosurgery, General University Hospital of Alexandroupolis, Alexandroupoli, Greece

'Department of Neurology, General Hospital of Papageorgiou, Thessaloniki, Greece

dDepartment of Neurology, General University Hospital of Alexandroupolis, Alexandroupoli, Greece

eDepartment of Radiology, General University Hospital of Alexandroupolis, Alexandroupoli, Greece

${ }^{f}$ Corresponding Author: Ioannis Siasios, Department of Neurosurgery, General Hospital of Papageorgiou, Ring Road, Pavlou Mela 56403, Thessaloniki, Greece. Email: siasiosj@yahoo.gr

doi: https://doi.org/10.14740/jocmr4551 sion. Larger multicenter clinical studies are a necessity in defining the role of the muscle component of the cervical spine in the surgical treatment of DDD.

Keywords: Cervical spine; Degenerative disease; Magnetic resonance imaging; Muscles

\section{Introduction}

Degenerative disc disease (DDD) is one of the most frequently encountered conditions in everyday clinical practice resulting in chronic back and neck pain, spinal instability and inevitably in functionality impairment $[1,2]$. The diminution of quality of life and depressive illness are some of the common findings among patients with DDD $[2,3]$. There is a consensus among scientists regarding the mechanism of DDD that aging along with environmental and genetic factors lead to cellular and structural alterations of the intervertebral disk, affecting its mechanic properties $[2,4,5]$. Consequently, nearby connective tissue structures undergo functional impairment and degeneration as well $[4,5]$. The associated neural elements may be compromised via mechanical compression or inflammatory process, which may warrant surgical treatment. Thus, clinical manifestations of spine degeneration could range from chronic pain to acute neurological deficits and myelopathy signs such as spasticity and gait impairment $[2,6]$. Tobacco use, diabetes, malnutrition, hip arthritis, spine trauma, hard physical work, lack of exercise and obesity have been linked with increased risk of DDD $[2,7]$.

Mainly two components are responsible for the mechanical stability of the neck, the cervical musculature $(80 \%)$ and the osseo-ligamentous system $(20 \%)[8,9]$. Although the osseo-ligamentous system has been meticulously studied during the last decades, cervical musculature still remains a less studied component of the neck with several recognized significant roles. According to the literature, cervical muscles preserve the cervical alignment, and contribute significantly in the mobility of the neck and the stabilization of the head. Neck pain, pathological alignment and decreased range of motion for example, could be the result of dysfunction of extensor cervical spine 
muscles $[10,11]$.

As stated in many studies in the past, cervical muscle volume tends to decrease in time with subsequent decline of the muscular strength even in asymptomatic populations and with preference in males [12-14]. Cervical spine muscle volume decrease becomes more apparent between the fifth to sixth decade of life and it has been found to be associated with shoulder stiffness when it affects deep extensor cervical muscles [14]. One of the most ordinary findings in magnetic resonance imaging (MRI) studies of the cervical spine is fat infiltration of the muscles [15]. Fat infiltration is associated with reduction of cervical lordosis and neck stiffness [16-18].

Surgical treatment of cervical spine pathologies requires cervical muscle manipulation either imperceptible as in anterior approaches where the muscles are usually divided, or significant as in posterior approaches where the muscles are detached from the spine. Although the literature is filled with studies concerning the multifactorial role of the muscles of the cervical spine, there is a lack of case series of surgically treated patients focusing on the role of cervical spine muscle layers to the clinical and surgical outcome.

Our goal is to identify in the current literature case series of surgically treated patients for degenerative cervical spine disease where any information regarding cervical musculature, based on preoperative MRI studies, has been recorded and used by the authors. Furthermore, our intention is to demonstrate the impact of cervical musculature in cervical lordosis alternations as well as pain and patient's functional outcome.

\section{Materials and Methods}

A search through the PubMed database was conducted from January 1990 to December 2020 using the following terms: "anterior," "cervical," "discectomy," "functional," "fusion," "laminectomy," "lordosis," "magnetic resonance imaging," "muscles," "operation," "procedure," "posterior," and "surgery". Only English language titles, abstracts, articles, and their references were retrieved. We included all the surgical series of patients that were treated for DDD and/or myelopathy in their cervical spine. Case series that recorded measurements of cervical muscles of any kind as well as patients' postoperative functional outcome were studied thoroughly. Additionally, any other information regarding cervical lordosis changes and pain scores were also recorded.

\section{Results}

According to our search, eleven studies were found, four of which were prospective and seven retrospective. Six studies were concentrated on anterior approaches (Table 1 [19-23]) and five studies on posterior approaches in the cervical spine (Table 2 [24-29]).

\section{Anterior approaches}

In their retrospective study, Choi et al (2016) focused on the relationship between deeply located paraspinal muscles and fusion after an anterior cervical spine procedure in 243 patients [19]. Authors studied the cross-sectional area (CSA) of these muscles and the related fusion based on bone union after anterior cervical discectomy and fusion (ACDF) surgery with a stand-alone cage at $\mathrm{C} 5 / \mathrm{C} 6$ or $\mathrm{C} 6 / \mathrm{C} 7$ levels. The CSAs included measurements of longus colli, longus capitis, semispinalis cervicis, and multifidus muscles based on magnetic resonance images. Postoperative dynamic radiographs were used for the evaluation of bone fusion. Patients were divided into two groups based on adequate/successful or inadequate fusion. According to their statistical results, extensor semispinalis cervicis and multifidus muscles were significantly heterogeneous among the two groups. More specifically, increased dimensions of extensor semispinalis cervicis at C5/C6 level was found positively correlated with a successful and quicker fusion process.

In another prospective study, Matsumoto et al (2012) studied the changes of posterior cervical spine muscles 10 years after an ACDF surgery in comparison to healthy subjects [20]. Authors enrolled 31 patients that were operated with an ACDF approach and 32 healthy adults as control group. A follow-up MRI was carried out on both groups and CSAs of deeply located posterior muscles were compared at $\mathrm{C} 3 / \mathrm{C} 4, \mathrm{C} 4 / \mathrm{C} 5$ and $\mathrm{C} 5 / \mathrm{C} 6$ levels. According to their measurements posterior cervical muscles varied significantly between the two groups with only a small depletion in the CSA in the ACDF group. These changes were not significantly correlated to pain or functionality scores as in posterior approaches.

Similarly, Thakar et al (2014) in their retrospective case control study focused on the impact of superficial, deep flexors and deep extensors cervical paraspinal muscles in patient's functionality and cervical sagittal alignment after a cervical corpectomy with fusion and plating for cervical spondylotic myelopathy (CSM) [21]. Sixty-seven patients were enrolled in this study. Authors collected data of CSAs of the paraspinal muscles based on axial MR images of T2-weighted sequence and calculated them as ratios in relation to the corresponding vertebral body areas (VBAs) and additionally as flexor/ extensor CSA ratios. The calculated fractions were correlated to the same fractions of normal subjects. In addition, these ratios were correlated to other parameters such as pain scores, Nurick grade and segmental angle change after surgery. Statistical analysis revealed that normal population had significant higher ratios than patients group $(\mathrm{P}<0.001)$. Higher age patients and female patients had a lower total extensor CSA/VBA ratio $(\mathrm{P}<0.001)$, while a longer period of clinical manifestations of CSM significantly prognosticated a higher total flexor/total extensor CSA ratio $(\mathrm{P}=0.02)$. Amongst the fractions reflecting the muscle areas, the deep flexor (DF)/ deep extensor (DE) fraction was found negatively correlated with segmental angle change in the subdivision of patients with preoperative straight or kyphotic segmental angles $(\mathrm{P}=$ 0.04 in the single corpectomy group, $\mathrm{P}=0.01$ in the two-level corpectomy group). There was not any statistically significant correlation of any of the calculated muscle fractions with $\mathrm{Nu}-$ rick grade alteration.

In continuation of his research background, Thakar et al (2019) prospectively studied 45 patients with single-level ra- 
Table 1. MRI-Based Studies of Cervical Spine Musculature of Patients That Underwent an Anterior Approach for Degenerative Disc Disease

\begin{tabular}{|c|c|c|c|c|}
\hline $\begin{array}{l}\text { Authors/year } \\
\text { of publication }\end{array}$ & Type of study & Number of patients & $\begin{array}{l}\text { Type of } \\
\text { surgery }\end{array}$ & Conclusions \\
\hline $\begin{array}{l}\text { Choi et al, } \\
2016 \text { [19] }\end{array}$ & $\begin{array}{l}\text { Retrospective } \\
\text { case-control } \\
\text { study }\end{array}$ & $\begin{array}{l}243 \text { divided in fusion } \\
\text { and no fusion groups }\end{array}$ & $\mathrm{ACDF}$ & $\begin{array}{l}\text { Increased dimensions of extensor semispinalis cervicis at } \mathrm{C} 5 / \\
\mathrm{C} 6 \text { level was found positively correlated with a successful and } \\
\text { quicker fusion process. }\end{array}$ \\
\hline $\begin{array}{l}\text { Matsumoto et } \\
\text { al, } 2012[20]\end{array}$ & $\begin{array}{l}\text { Prospective } \\
\text { case-control } \\
\text { study }\end{array}$ & $\begin{array}{l}31 \text { patients that were } \\
\text { operated with ACDF } \\
\text { approach, and } 32 \text { healthy } \\
\text { adults as control group }\end{array}$ & $\mathrm{ACDF}$ & $\begin{array}{l}\text { Posterior cervical muscles were not different significantly } \\
\text { between the two groups with only a small decrease in the cross- } \\
\text { sectional area (CSA) in the ACDF group. These changes were } \\
\text { not significantly correlated to pain or functionality scores. }\end{array}$ \\
\hline $\begin{array}{l}\text { Thakar et al, } \\
2014 \text { [21] }\end{array}$ & $\begin{array}{l}\text { Retrospective } \\
\text { case-control } \\
\text { study }\end{array}$ & $\begin{array}{l}67 \text { patients with cervical } \\
\text { spondylotic myelopathy } \\
\text { and normal subjects }\end{array}$ & $\begin{array}{l}\text { Anterior } \\
\text { cervical } \\
\text { corpectomy- } \\
\text { fusion-plating }\end{array}$ & $\begin{array}{l}\text { Normal population has significant higher ratios of CSAs of } \\
\text { the superficial, deep flexor }(\mathrm{DF}) \text {, and deep extensor }(\mathrm{DE}) \\
\text { paraspinal muscles than patients' group }(\mathrm{P}<0.001) \text {. Higher } \\
\text { age patients and female patients had a lower total extensor } \\
\text { CSA/VBA ratio }(\mathrm{P}<0.001) \text {, while a longer duration of } \\
\text { symptoms significantly predicted a greater total flexor/total } \\
\text { extensor CSA ratio }(\mathrm{P}=0.02) \text {. Among the muscle area ratios, } \\
\text { the } \mathrm{DF} / \mathrm{DE} \text { ratio demonstrated a negative correlation with } \\
\text { segmental angle change in the subgroup with preoperative } \\
\text { straight or kyphotic segmental angles }(\mathrm{P}=0.04 \text { in the single } \\
\text { corpectomy group, } \mathrm{P}=0.01 \text { in the two-level corpectomy } \\
\text { group). There was no correlation of any of the muscle ratios } \\
\text { with change in Nurick grade. }\end{array}$ \\
\hline $\begin{array}{l}\text { Thakar et al, } \\
2019 \text { [22] }\end{array}$ & $\begin{array}{l}\text { Prospective } \\
\text { study }\end{array}$ & $\begin{array}{l}45 \text { patients with single } \\
\text { level radiculopathy- } \\
\text { myelopathy or myelopathy }\end{array}$ & $\mathrm{ACDF}$ & $\begin{array}{l}\text { Deep flexors areas as well as the ratio of deep flexors } \\
\text { areas to deep extensors areas have a significant } \\
\text { prognostic value of Nurick grade improvement. }\end{array}$ \\
\hline $\begin{array}{l}\text { Wong et al, } \\
2020 \text { [23] }\end{array}$ & $\begin{array}{l}\text { Retrospective } \\
\text { case-control } \\
\text { study }\end{array}$ & $\begin{array}{l}32 \text { patients with adjacent } \\
\text { level disease after a two- } \\
\text { level ACDF procedure; } \\
30 \text { patients that did not } \\
\text { have this complication }\end{array}$ & $\mathrm{ACDF}$ & $\begin{array}{l}\text { Asymmetry of fat at C5 (coefficient: } 0.06 \text { ), standardized } \\
\text { measures of C7 lean (coefficient: } 0.05 \text { ) and total CSA } \\
\text { measures (coefficient: } 0.05 \text { ) were the strongest predictors of } \\
\text { early onset ASD. }\end{array}$ \\
\hline
\end{tabular}

MRI: magnetic resonance imaging; ACDF: anterior cervical discectomy and fusion; VBA: vertebral body area; ASD: adjacent segment degeneration.

diculopathy (myelopathy or myelopathy) that underwent an anterior cervical discectomy (ACD) procedure [22]. The main goal was to record all the possible predictors of the surgical outcome, as stated from the literature, and to study their significance. Many parameters were taken into consideration such as age, gender, smoking, other comorbidities, duration of symptoms, preoperative Nurick grade, extent of cord compression, and signal intensity change in the spinal cord. Additionally, MRI-based CSAs of the superficial and deep paraspinal muscles were included. According to author's statistics, deep flexors' areas as well as the ratio of deep flexors' areas to deep extensors areas have a significant prognostic value of Nurick grade improvement.

Lastly, another research group retrospectively studied the predictive value of morphology of semispinalis cervicis and multifidus muscles in adjacent level degeneration disease after ACD and fusion surgery [23]. Wong et al (2020) created two matched groups of patients. One group had 32 patients with adjacent level disease after a two-level ACDF procedure. The other group had 30 patients with a normal postoperative course. The total CSA of deep neck muscles and lean muscles from $\mathrm{C} 3$ to $\mathrm{C} 7$ was calculated focusing in asymmetry on each operated level by using T2-weighted MRI. An algorithm was used in order to predict proximal or distal adjacent segment degeneration (ASD) which was supported by a vector machine. According to the results of this study, the used algorithm predicted early ASD with high accuracy (96.7\%). Fat asymmetry at C5 (coefficient: 0.06), standardized measures of C7 lean (coefficient: 0.05 ) and total CSAs measures (coefficient: 0.05) were the dominant predictors of early onset ASD.

\section{Posterior approaches}

Ashana et al (2017) compared the presence of paraspinal muscle atrophy between patients that were operated with laminoplasty and patients that were operated with laminectomy and fusion [24]. Both groups of patients were operated for CSM. Atrophy was recorded as percentage change in CSAs of the cervical paraspinal muscles from preoperative to postoperative MRI studies. Authors found a 2.19 times increase of the degree of atrophy in patients who sustained laminectomy and fusion. This study concluded that paraspinal muscle atrophy is correlated to anatomically extended surgical procedures where 
Table 2. MRI-Based Studies of Cervical Spine Musculature of Patients That Underwent a Posterior Approach for Degenerative Disc Disease

\begin{tabular}{|c|c|c|c|c|}
\hline $\begin{array}{l}\text { Authors/year } \\
\text { of publication }\end{array}$ & Type of study & $\begin{array}{l}\text { Number } \\
\text { of patients }\end{array}$ & Type of surgery & Conclusions \\
\hline $\begin{array}{l}\text { Ashana et al, } \\
2017[24]\end{array}$ & $\begin{array}{l}\text { Retrospective } \\
\text { study }\end{array}$ & 61 & $\begin{array}{l}18 \text { laminoplasty and } 43 \\
\text { laminectomy and fusion patients }\end{array}$ & $\begin{array}{l}\text { Authors found a } 2.19 \text { times increase of the degree of } \\
\text { atrophy in patients who sustained laminectomy and fusion. } \\
\text { This study concluded that paraspinal muscle atrophy is } \\
\text { correlated to anatomically larger surgical procedures. }\end{array}$ \\
\hline $\begin{array}{l}\text { Chen et al, } \\
2019[25]\end{array}$ & $\begin{array}{l}\text { Retrospective } \\
\text { study }\end{array}$ & 63 & $\begin{array}{l}36 \text { patients with laminoplasty } \\
\text { and posterior muscle-ligament } \\
\text { complex preservation, } \\
\text { and } 27 \text { patients with } \\
\text { traditional laminoplasty }\end{array}$ & $\begin{array}{l}\text { The preservation of posterior muscle-ligament } \\
\text { complex protects patients from a postoperative } \\
\text { muscle volume decrease which was noted in the } \\
\text { traditional laminoplasty patients' group }(\mathrm{P}<0.01) \text {. }\end{array}$ \\
\hline $\begin{array}{l}\text { Kim et al, } \\
2020[26]\end{array}$ & $\begin{array}{l}\text { Retrospective } \\
\text { study }\end{array}$ & 106 & Cervical laminoplasty & $\begin{array}{l}\text { Higher } \mathrm{T} 1 \text { slope and less regional cross- } \\
\text { sectional areas at } \mathrm{C} 7 \text { - } \mathrm{T} 1 \text { level were } \\
\text { associated with loss of cervical lordosis. }\end{array}$ \\
\hline $\begin{array}{l}\text { Kotani et al, } \\
2012[28]\end{array}$ & $\begin{array}{l}\text { Prospective } \\
\text { study }\end{array}$ & 90 & $\begin{array}{l}\text { Conventional open-door } \\
\text { laminoplasty and deep extensor } \\
\text { muscle-preserving laminoplasty }\end{array}$ & $\begin{array}{l}\text { There is a superiority of deep extensor muscle-preserving } \\
\text { laminoplasty in terms of postoperative axial pain, QOL, and } \\
\text { prevention of atrophy of the deep extensor muscles over } \\
\text { conventional open-door laminoplasty for the treatment of } \\
\text { CSM. }\end{array}$ \\
\hline $\begin{array}{l}\text { Lee et al, } \\
2018 \text { [29] }\end{array}$ & $\begin{array}{l}\text { Prospective } \\
\text { study }\end{array}$ & 144 & Laminoplasty procedure & $\begin{array}{l}\text { Statistical analysis revealed that high T1 slope and low } \\
\text { summation of CSAs at each level of the semispinalis } \\
\text { cervicis is correlated with loss of cervical lordosis. } \\
\text { The level of the semispinalis cervicis associated } \\
\text { with greater loss of lordosis was the C6 level. }\end{array}$ \\
\hline
\end{tabular}

MRI: magnetic resonance imaging; CSA: cross-sectional area; QOL: quality of life; CSM: cervical spondylotic myelopathy.

surgical manipulations and muscle detachment are more prominent [24].

Chen et al (2019) retrospectively compared the differences on surgical results between 36 patients with CSM that were treated with laminoplasty and posterior muscle-ligament complex preservation, and 27 patients with the same pathology treated with traditional laminoplasty [25]. Among others, the authors concluded that the preservation of posterior muscle-ligament complex protects patients from a postoperative muscle volume decrease which was noted in the traditional laminoplasty group of patients $(\mathrm{P}<0.01)$. Pain scores as well as cervical sagittal balance were better in the first group of patients.

Kim et al (2020) in their retrospective study attempted to recognize predisposing factors of loss of cervical lordosis in 106 patients that underwent a cervical laminoplasty procedure [26]. Authors divided their patients in 38 that preserved cervical lordosis and in 68 patients that lost cervical lordosis. They recorded cervical sagittal parameters, neck pain scores, CSAs of the posterior cervical muscles in the operated levels and muscle fat infiltration of deep extensor cervical muscles based on preoperative MRIs. Authors concluded that besides cervical sagittal parameters such as higher T1 slope, lesser regional
CSAs at C7 - T1 level were associated with loss of cervical lordosis as well.

In their retrospective cohort study, Kotani et al (2009) compared the conventional surgical treatment of open-door laminoplasty with deep extensor muscle preserving laminoplasty in cervical myelopathy patients [27]. Besides the typical recorded parameters in surgically treated patients such as axial pain and quality of life, parameters such as radiological evaluation of cervical lordosis, range of motion and deep extensor muscle areas on specific axial MRI images were also taken into consideration. Eighty-four patients were included in this study with a minimum follow-up period of 24 months. According to the results of this study, a statistically significant difference in superior cervical spine function, quality of life, as well as pain reduction scores were noted in the muscle preserving group indicating the superiority of this method. This was supported also by the MRI radiological evaluation which demonstrated statistically significant muscle atrophy in patients that were treated by the conventional method $(\mathrm{P}<$ 0.01). In 2012, the same group of researchers published data of 90 patients that were treated for CSM with a minimum follow-up of 36 months [28]. These patients were divided also in two groups and the protocol of comparison was identical 
by using the two aforementioned surgical techniques. Authors concluded that pain, functionality and muscle atrophy were statistically different in these two groups. The muscle preserving technique proved to be superior to the conventional laminoplasty.

In another similar study, Lee et al (2018) focused on the role of preoperative CSA of semispinalis cervicis muscle in the preservation of cervical lordosis after a laminoplasty procedure [29]. One hundred forty-four patients with cervical myelopathy were included in this study. Cervical sagittal balance parameters and MRI-based CSAs of semispinalis cervicis muscle were recorded for every patient. Statistical analysis showed that high T1 slope and low summation of CSAs at each level of the semispinalis cervicis were correlated with loss of cervical lordosis. The level of the semispinalis cervicis that was associated with substantial loss of lordosis was the C6 level with a max of 10 degrees reduction of cervical lordosis being noted.

\section{Discussion}

Cervical spine muscles can be divided to suboccipital region muscles and to mid to lower cervical spine muscles [30]. The last are divided based on their location to: ventrally located muscles and dorsally located muscles. The ventral muscle layer is further subdivided to: 1) superficial muscles such as platysma and sternocleidomastoid muscle; 2) deep muscle layer such as: scalenus group, longus group and infrahyoid group. In the same way, the dorsal muscle layer is further divided to: 1) superficial muscle layer such as trapezius, splenius and elevator scapulae muscles; 2) the intermediate muscle layer known as erector spinae group including semispinalis, iliocostalis, and longissimus muscles; 3 ) deep muscle layer group which includes the transversospinalis muscle group. Based on their function, cervical muscles can be further divided to flexors, extensors, lateral flexors and rotators (Table 3) [30].

In anterior approaches, the muscles being manipulated are the sternocleidomastoid, the platysma, omohyoid, sternothyroid and bilateral longus colli [31-35]. The spine surgeon usually divides the muscles with the exception of the platysma and the omohyoid, which can be transected, and the longus colli that normally are detached from the anterior surface of the cervical spine. In posterior approaches, the posterior paraspinal muscles are detached from the spine in order to gain access to underlying significant anatomical structures such as the spinous process, the laminae, the facets, the pedicles, the neuronal foramens, the vertebrae, the spinal canal and the spinal cord [36-44]. The degree of detachment depends on the pathology and the type of the procedure (laminectomy/laminectomies, foraminotomies, posterior fusion with screws and rods, etc). The main dorsal muscles that are affected from these surgical procedures are trapezius, splenius, semispinalis (capitis and cervicis) and longissimus depending on the operated level/levels.

MRI of the cervical spine is a commonly used imaging study that spine surgeons use preoperatively in order to extract useful information about the cervical discs and spinal
Table 3. Classification of Cervical Spine Muscles Based on Their Function

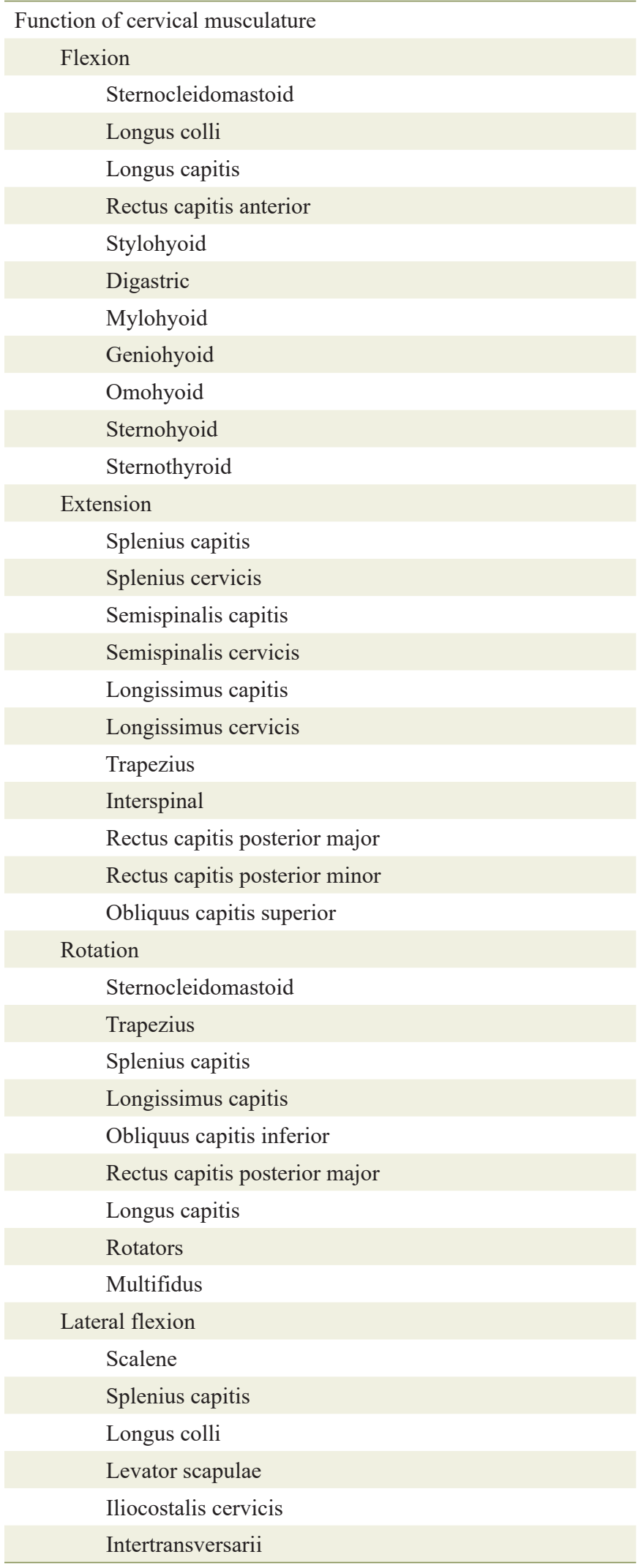




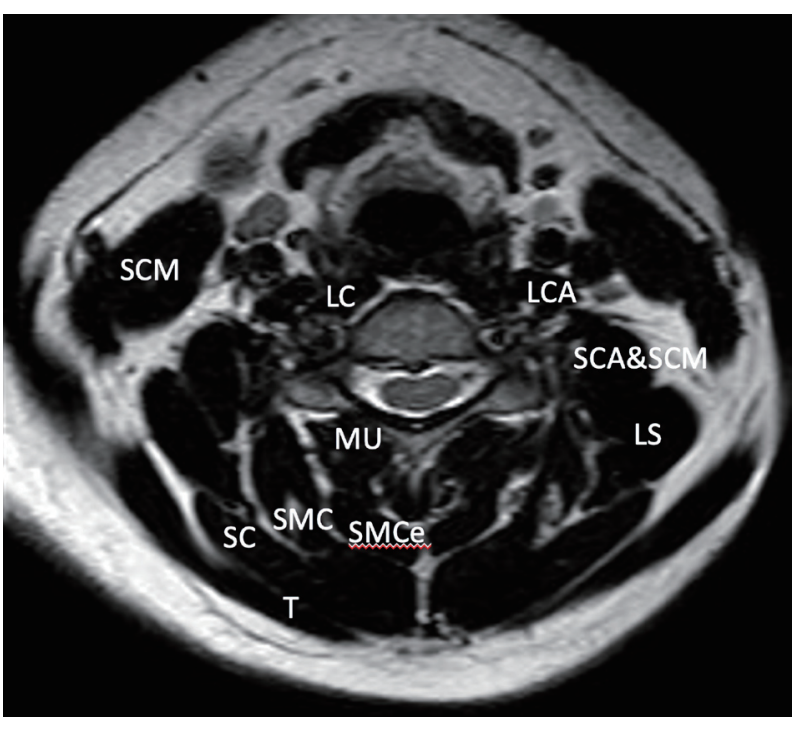

Figure 1. Axial T2 MRI image that demonstrates the muscle layers of the cervical spine of a 40-year-old asymptomatic woman at C5/C6 level. MRI: magnetic resonance imaging; LCA: longissimus capitis; LC: longus colli; LS: levator scapulae; MU: multifidus; SCA: scalenus anterior; SC: splenius capitis; SMC: semispinalis capitis; SCM: sternocleidomastoid; SMCe: semispinalis cervicis; T: trapezius.

cord morphology [45-49]. Interestingly, cervical spine MRI through several well-known MR applications such as T1, T2, proton density and gradient echo can also depict the muscle layers of the cervical spine and additionally locate pathological signal areas such as infiltrated muscle fat $[16,17,50-52]$. The collected data based on MRI studies can assist in the volume quantification as well as qualification of the cervical spine muscles morphology (Fig. 1). In the literature, there are several studies analyzing muscle morphology with a variety of imaging protocols as well as studied populations including young people, elderly people, healthy people, trauma and degenerative cases. Elliot et al in their work tried to define imaging protocols that could provide adequate information about paravertebral muscles volume and their components [51]. They spotted several different imaging protocols in the literature based on T1, T2, STIR, DIXON and T2-fat suppression sequences. Furthermore, the collected slices of interest based on axial MR images as well as the studied muscles of interest varied also significantly (by several cervical disc spaces) with manual based as well as automated based measurements of regions of interest (ROIs). Authors concluded that a multi-slice approach by using three-dimensional (3D)-MRI techniques could define muscle size and muscle fat infiltration although it requires significant effort and time [51]. High resolution MRI techniques such as 3D fat/water discrimination and proton density fat suppression/fraction can be used towards the definition of cervical muscles morphology [51]. In our literature review study, heterogenicity of imaging protocols was also noted. Measurements were focused mostly on deep paraspinal extensor muscles based on their CSAs in axial MR images at specific cervical spine levels.

Additionally, there were several studies in the past linking muscle fat infiltration and subsequently muscle's atrophy with posttraumatic pain especially after a whiplash injury $[52,53]$. This finding was noted in cervical extensors and cervical flexors of the neck of patients with whiplash cervical trauma [11]. Muscle fat infiltration is also present in cervical myelopathy patients and is highly associated with patients' reduced sensorimotor functionality and muscle volume loss [54]. In several studies, muscle fat infiltration and asymmetry of deeply located paraspinal muscles have been linked with higher Neck Disability Index scores as well as weakness and pathological pyramidal signs $[55,56]$. Moreover, in a recent study, the authors expressed the opinion that muscle fat infiltration of the upper extensor muscles is linked to loss of cervical lordosis while fat infiltration of the lower extensors cervical muscles can lead to significant loss of patient's functionality [15]. In addition to that, it has been found that chronic neck pain patients have a tendency through time to present reduced balance as well as muscle atrophy combined with muscle fat infiltration $[18,57]$. Worse deformity status has been found in cervical deformity patients with notable muscle fat infiltration and muscle atrophy of their posterior extensor cervical muscles [58]. Surgical treatment of cervical deformity can lead to reduction of muscle fat infiltration of posterior extensor muscles and is associated with better muscle tone and also pain diminution [59]. All these statements still need clarification as several scientists claim that pain could be the result of degeneration of the anatomical components of the cervical spine such as vertebrae, facets and discs and the correlated changes of spine curvature [20].

As the literature demonstrated, in patients with cervical degenerative disease as well as myelopathy, muscle atrophy is a common finding in patients with higher pain scores as well as higher disability scores after a cervical spine procedure especially posterior and traditional $[19,20,24,25,27,28,60]$. The preservation of the cervical muscle attachments appears to positively affect the postoperative pain score and muscle atrophy [60]. Muscle fat infiltration and CSAs measurements of deep posterior cervical spine muscles in one study can predict adjacent level degeneration disease after an ACDF procedure [23]. Furthermore, in another study optimum fusion process was noticed in patients with increased muscle volume of extensor semispinalis cervicis [19].

Regarding the role of cervical spine muscles in the preservation of cervical spine lordosis, there are many facts published in the literature supporting their strong connection. For example, botulinum toxin injection can deteriorate cervical spine kyphotic deformity [61]. Drop head syndrome can be the result of cervical spondylotic amyotrophy [62]. In general, in patients with CSM there is a significant correlation between cervical muscles morphology, clinical findings and patients' functionality [55]. Tamai et al in their study found a significant correlation between paraspinal muscle volume, cervical sagittal balance parameters and DDD based on retrospectively collected kinematic cervical spine MRI data of patients with DDD [63]. Cervical extensors isometric exercises can reduce neck pain and contribute in cervical lordosis restoration [64]. Patients with loss of cervical lordosis have less muscular strength especially in their extensors [10]. According to a recent study, cranio-cervical flexor muscles exercise can reduce neck pain and improve cervical spine lordosis [65]. Additionally, May- 
oux-Benhamou et al concluded, in their study, that longus colli muscles interact with post-cervical muscle layers for the stabilization of the cervical spine and head as well as the preservation of cervical lordosis [66]. Similarly, Mitsutake et al in their study concluded that in patients with cervical spondylotic radiculopathy, muscle fat infiltration of cervical multifidus muscle is linked to postural instability even in static standing positions [67]. Furthermore, it is supported in the literature that muscle fat infiltration of the upper cervical extensors muscles can lead to loss of cervical lordosis and in the case of lower cervical extensors to functionality impairment [15]. In another published clinical study, the authors tried to correlate muscle fat infiltration with cervical motion based on cervical kinetic MRI of patients with clinical signs of radiculopathy and/or neck pain [68]. Authors concluded that presence of muscle fat infiltration was more obvious at $\mathrm{C} 3, \mathrm{C} 7$ levels than other intermediate cervical spine levels [68]. Cervical spine mobilization as well as lordosis was not affected by the degree of muscle fat infiltration [68].

According to our literature research study, in surgically treated patients for DDD, the strong connection between cervical lordosis and the muscle component of the cervical spine seems to be present. In anterior approaches, the ratio of deep flexor to deep extensor paraspinal muscles proved to have a negative correlation with segmental angle change in patients with straight or kyphotic segmental angles [21]. In regards to posterior approaches, there are studies supporting that less regional CSAs at C7 - T1 level and low summation of CSAs at each level of the semispinalis cervicis are correlated to reduced cervical lordosis [29]. Fusion process was studied only in anterior approaches, as it has been found that increased dimensions of extensor semispinalis cervicis at $\mathrm{C} 5 / \mathrm{C} 6$ level, lack of fat asymmetry at $\mathrm{C} 5$, standardized measures of $\mathrm{C} 7$ lean and total CSA measures are significantly correlated with the timing of fusion and the prediction of ASD [19, 23].

Additionally, functionality expressed by Nurick scores was significantly correlated to deep flexors areas as well as the ratio of deep flexors to deep extensors areas in anterior approaches only in one study [22]. In posterior approaches, the preservation of posterior paraspinal muscles by applying new techniques demanding less muscle manipulation could lead to improved functionality and reduced pain scores [27, 28].

In conclusion, there are several surgical case series in the literature studying cervical spine musculature with large heterogenicity in patients' selection, imaging study protocols, applied measurements as well as study goals. It is remarkable that the muscle component is far less studied than the cervical spine itself. Muscle layers of the cervical spine seem to be valuable structures for the preservation of cervical lordosis, the improvement of the patients' functionality, as well as the prediction of surgical outcome in DDD. Finally, larger multicenter clinical studies could help in defining the role of the muscle component of the cervical spine in the surgical outcome of DDD.

\section{Acknowledgments}

None to declare.

\section{Financial Disclosure}

This research did not receive any specific grant from funding agencies in the public, commercial, or not-for-profit sectors.

\section{Conflict of Interest}

None to declare.

\section{Author Contributions}

Conception and design: Ioannis Siasios and Theodosis Birbilis. All authors contributed to data acquisition, data interpretation, drafting the manuscript, critically revising the manuscript, and final approval of the manuscript.

\section{Data Availability}

The authors declare that data supporting the findings of this study are available within the article.

\section{Abbreviations}

ALD: adjacent level disease; ACDF: anterior cervical decompression and fusion; CSAs: cross-sectional areas; DDD: degenerative disc disease; DF: deep flexor; DE: deep extensor; MRI: magnetic resonance imaging; VBAs: vertebral body areas

\section{References}

1. Garczyk D, Jankowski R, Misterska E, Glowacki M, Zukiel R, Kowalska AM. Patient satisfaction with nursing after surgery due to cervical or lumbar discopathy. Med Sci Monit. 2013;19:892-902.

2. Kos N, Gradisnik L, Velnar T. A brief review of the degenerative intervertebral disc disease. Med Arch. 2019;73(6):421-424.

3. Jablonska R, Slusarz R, Krolikowska A, Haor B, Antczak A, Szewczyk M. Depression, social factors, and pain perception before and after surgery for lumbar and cervical degenerative vertebral disc disease. J Pain Res. 2017;10:89-99.

4. Podichetty VK. The aging spine: the role of inflammatory mediators in intervertebral disc degeneration. Cell Mol Biol (Noisy-le-grand). 2007;53(5):4-18.

5. Sainoh T, Inage K, Orita S, Koda M, Furuya T, Yamauchi $\mathrm{K}$, Suzuki M, et al. Correlation among inflammatory cytokine expression levels, degree of disk degeneration, and predominant clinical symptoms in patients with degenerated intervertebral discs. Asian Spine J. 2017;11(3):472477.

6. Nouri A, Tetreault L, Singh A, Karadimas SK, Fehlings 
MG. Degenerative cervical myelopathy: epidemiology, genetics, and pathogenesis. Spine (Phila Pa 1976). 2015;40(12):E675-693.

7. Steelman T, Lewandowski L, Helgeson M, Wilson K, Olsen C, Gwinn D. Population-based risk factors for the development of degenerative disk disease. Clin Spine Surg. 2018;31(8):E409-E412.

8. Panjabi MM. Cervical spine models for biomechanical research. Spine (Phila Pa 1976). 1998;23(24):2684-2700.

9. Panjabi MM, Cholewicki J, Nibu K, Grauer J, Babat LB, Dvorak J. Critical load of the human cervical spine: an in vitro experimental study. Clin Biomech (Bristol, Avon). 1998;13(1):11-17.

10. Alpayci M, Senkoy E, Delen V, Sah V, Yazmalar L, Erden M, Toprak M, et al. Decreased neck muscle strength in patients with the loss of cervical lordosis. Clin Biomech (Bristol, Avon). 2016;33:98-102.

11. De Pauw R, Coppieters I, Kregel J, De Meulemeester K, Danneels L, Cagnie B. Does muscle morphology change in chronic neck pain patients? - A systematic review. Man Ther. 2016;22:42-49.

12. Booth FW, Weeden SH, Tseng BS. Effect of aging on human skeletal muscle and motor function. Med Sci Sports Exerc. 1994;26(5):556-560.

13. Janssen I, Heymsfield SB, Wang ZM, Ross R. Skeletal muscle mass and distribution in 468 men and women aged 18-88 yr. J Appl Physiol (1985). 2000;89(1):81-88.

14. Okada E, Matsumoto M, Ichihara D, Chiba K, Toyama Y, Fujiwara H, Momoshima S, et al. Cross-sectional area of posterior extensor muscles of the cervical spine in asymptomatic subjects: a 10-year longitudinal magnetic resonance imaging study. Eur Spine J. 2011;20(9):1567-1573.

15. Kim CY, Lee SM, Lim SA, Choi YS. Impact of Fat Infiltration in Cervical Extensor Muscles on Cervical Lordosis and Neck Pain: A Cross-Sectional Study. Clin Orthop Surg. 2018;10(2):197-203.

16. Elliott J, Jull G, Noteboom JT, Darnell R, Galloway G, Gibbon WW. Fatty infiltration in the cervical extensor muscles in persistent whiplash-associated disorders: a magnetic resonance imaging analysis. Spine (Phila $\mathrm{Pa}$ 1976). 2006;31(22):E847-855.

17. Elliott J, Sterling M, Noteboom JT, Darnell R, Galloway G, Jull G. Fatty infiltrate in the cervical extensor muscles is not a feature of chronic, insidious-onset neck pain. Clin Radiol. 2008;63(6):681-687.

18. Hallgren RC, Greenman PE, Rechtien JJ. Atrophy of suboccipital muscles in patients with chronic pain: a pilot study. J Am Osteopath Assoc. 1994;94(12):1032-1038.

19. Choi MK, Kim SB, Park CK, Lee SH, Jo DJ. Relation of deep paraspinal muscles' cross-sectional area of the cervical spine and bone union in anterior cervical decompression and fusion: a retrospective study. World Neurosurg. 2016;96:91-100.

20. Matsumoto M, Okada E, Ichihara D, Watanabe K, Chiba $\mathrm{K}$, Toyama Y, Fujiwara H, et al. Changes in the crosssectional area of deep posterior extensor muscles of the cervical spine after anterior decompression and fusion: 10-year follow-up study using MRI. Eur Spine J. 2012;21(2):304-308.
21. Thakar S, Mohan D, Furtado SV, Sai Kiran NA, Dadlani R, Aryan S, Rao AS, et al. Paraspinal muscle morphometry in cervical spondylotic myelopathy and its implications in clinicoradiological outcomes following central corpectomy: clinical article. J Neurosurg Spine. 2014;21(2):223-230.

22. Thakar S, Arun AA, Aryan S, Mohan D, Hegde AS. Deep flexor sarcopenia as a predictor of poor functional outcome after anterior cervical discectomy in patients with myelopathy. Acta Neurochir (Wien). 2019;161(10):22012209.

23. Wong AYL, Harada G, Lee R, Gandhi SD, Dziedzic A, Espinoza-Orias A, Parnianpour M, et al. Preoperative paraspinal neck muscle characteristics predict early onset adjacent segment degeneration in anterior cervical fusion patients: A machine-learning modeling analysis. J Orthop Res. 2020.

24. Ashana AO, Ajiboye RM, Sheppard WL, Sharma A, Kay AB, Holly LT. Cervical Paraspinal Muscle Atrophy Rates Following Laminoplasty and Laminectomy with Fusion for Cervical Spondylotic Myelopathy. World Neurosurg. 2017; 107:445-450.

25. Chen C, Yang C, Yang S, Gao Y, Zhang Y, Wu X, Hua W, et al. Clinical and Radiographic Outcomes of modified unilateral open-door laminoplasty with posterior muscleligament complex preservation for cervical Spondylotic myelopathy. Spine (Phila Pa 1976). 2019;44(24):16971704.

26. Kim KR, Lee CK, Park JY, Kim IS. Preoperative Parameters for Predicting the Loss of Lordosis After Cervical Laminoplasty. Spine (Phila Pa 1976). 2020;45(21):14761484.

27. Kotani Y, Abumi K, Ito M, Sudo H, Takahata M, Ohshima S, Hojo Y, et al. Minimum 2-year outcome of cervical laminoplasty with deep extensor muscle-preserving approach: impact on cervical spine function and quality of life. Eur Spine J. 2009;18(5):663-671.

28. Kotani Y, Abumi K, Ito M, Sudo H, Takahata M, Nagahama K, Iwata A, et al. Impact of deep extensor musclepreserving approach on clinical outcome of laminoplasty for cervical spondylotic myelopathy: comparative cohort study. Eur Spine J. 2012;21(8):1536-1544.

29. Lee BJ, Park JH, Jeon SR, Rhim SC, Roh SW. Importance of the preoperative cross-sectional area of the semispinalis cervicis as a risk factor for loss of lordosis after laminoplasty in patients with cervical spondylotic myelopathy. Eur Spine J. 2018;27(11):2720-2728.

30. Alexander JT. Cervical spine and skull base anatomy. In: Edward C (editor). Surgical exposure of the spine: an extensile approach. Park Ridge, Illinois: Amer Assn of Neurological Surgeons; 1995:1-19.

31. Aronson N, Filtzer DL, Bagan M. Anterior cervical fusion by the smith-robinson approach. J Neurosurg. 1968;29(4):396-404.

32. Brodke DS, Zdeblick TA. Modified Smith-Robinson procedure for anterior cervical discectomy and fusion. Spine (Phila Pa 1976). 1992;17(10 Suppl):S427-430.

33. Cho W, Buchowski JM, Park Y, Maeda T, Nabb CE, Riew KD. Surgical approach to the cervicothoracic junction: 
can a standard Smith-Robinson approach be utilized? J Spinal Disord Tech. 2012;25(5):264-267.

34. Smith GW, Robinson RA. The treatment of certain cervical-spine disorders by anterior removal of the intervertebral disc and interbody fusion. J Bone Joint Surg Am. 1958;40-A(3):607-624.

35. Whitecloud TS, 3rd. Anterior surgery for cervical spondylotic myelopathy. Smith-Robinson, Cloward, and vertebrectomy. Spine (Phila Pa 1976). 1988;13(7):861-863.

36. Anderson PA, Matz PG, Groff MW, Heary RF, Holly LT, Kaiser MG, Mummaneni PV, et al. Laminectomy and fusion for the treatment of cervical degenerative myelopathy. J Neurosurg Spine. 2009;11(2):150-156.

37. Audat ZA, Barbarawi MM, Obeidat MM. Posterior cervical decompressive laminectomy and lateral mass screw fixation. Neurosciences (Riyadh). 2011;16(3):248-252.

38. Cho SK, Kim JS, Overley SC, Merrill RK. Cervical Laminoplasty: Indications, Surgical Considerations, and Clinical Outcomes. J Am Acad Orthop Surg. 2018;26(7):e142e152.

39. Epstein NE. Laminectomy for cervical myelopathy. Spinal Cord. 2003;41(6):317-327.

40. Gargiulo G, Girardo M, Rava A, Coniglio A, Cinnella P, Masse A, Fusini F. Clinical comparison between simple laminectomy and laminectomy plus posterior instrumentation in surgical treatment of cervical myelopathy. Eur J Orthop Surg Traumatol. 2019;29(5):975-982.

41. Kim BS, Dhillon RS. Cervical laminectomy with or without lateral mass instrumentation: a comparison of outcomes. Clin Spine Surg. 2019;32(6):226-232.

42. Lau D, Winkler EA, Than KD, Chou D, Mummaneni PV. Laminoplasty versus laminectomy with posterior spinal fusion for multilevel cervical spondylotic myelopathy: influence of cervical alignment on outcomes. J Neurosurg Spine. 2017;27(5):508-517.

43. Otani K, Iwabuchi M, Sato K, Konno S, Kikuchi S. Postoperative neck symptoms of posterior approach for cervical compressive myelopathy: Expansive open-door laminoplasty vs. segmental partial laminectomy. Fukushima J Med Sci. 2018;64(2):54-59.

44. Zhou W, Tang J, Fan J, Yin G. The effect of intramedullary signal intensity in MRI on the therapeutic efficacy of posterior cervical decompression laminectomy with internal fixation and fusion for multi-level cervical spondylotic myelopathy : a retrospective cohort study. Acta Orthop Belg. 2018;84(3):366-373.

45. Moll LT, Kindt MW, Stapelfeldt CM, Jensen TS. Degenerative findings on MRI of the cervical spine: an interand intra-rater reliability study. Chiropr Man Therap. 2018;26:43.

46. Clarencon F, Law-Ye B, Bienvenot P, Cormier E, Chiras J. The degenerative spine. Magn Reson Imaging Clin N Am. 2016;24(3):495-513.

47. Erly WK, Carmody RF. MRI of the spine. Crit Rev Diagn Imaging. 1994;35(4):313-377.

48. Kanna RM, Kamal Y, Mahesh A, Venugopal P, Shetty AP, Rajasekaran S. The impact of routine whole spine MRI screening in the evaluation of spinal degenerative diseases. Eur Spine J. 2017;26(8):1993-1998.
49. Pierre-Jerome C, Arslan A, Bekkelund SI. MRI of the spine and spinal cord: imaging techniques, normal anatomy, artifacts, and pitfalls. J Manipulative Physiol Ther. 2000;23(7):470-475.

50. Au J, Perriman DM, Pickering MR, Buirski G, Smith PN, Webb AL. Magnetic resonance imaging atlas of the cervical spine musculature. Clin Anat. 2016;29(5):643-659.

51. Elliott JM, Cornwall J, Kennedy E, Abbott R, Crawford RJ. Towards defining muscular regions of interest from axial magnetic resonance imaging with anatomical crossreference: part II - cervical spine musculature. BMC Musculoskelet Disord. 2018;19(1):171.

52. Elliott JM, Galloway GJ, Jull GA, Noteboom JT, Centeno CJ, Gibbon WW. Magnetic resonance imaging analysis of the upper cervical spine extensor musculature in an asymptomatic cohort: an index of fat within muscle. Clin Radiol. 2005;60(3):355-363.

53. Karlsson A, Leinhard OD, Aslund U, West J, Romu T, Smedby O, Zsigmond $\mathrm{P}$, et al. An Investigation of Fat Infiltration of the Multifidus Muscle in Patients With Severe Neck Symptoms Associated With Chronic Whiplash-Associated Disorder. J Orthop Sports Phys Ther. 2016;46(10):886-893.

54. Cloney M, Smith AC, Coffey T, Paliwal M, Dhaher Y, Parrish T, Elliott J, et al. Fatty infiltration of the cervical multifidus musculature and their clinical correlates in spondylotic myelopathy. J Clin Neurosci. 2018;57:208213.

55. Fortin M, Dobrescu O, Courtemanche M, Sparrey CJ, Santaguida C, Fehlings MG, Weber MH. Association between paraspinal muscle morphology, clinical symptoms, and functional status in patients with degenerative cervical myelopathy. Spine (Phila Pa 1976). 2017;42(4):232239.

56. Fortin M, Wilk N, Dobrescu O, Martel P, Santaguida C, Weber MH. Relationship between cervical muscle morphology evaluated by MRI, cervical muscle strength and functional outcomes in patients with degenerative cervical myelopathy. Musculoskelet Sci Pract. 2018;38:1-7.

57. McPartland JM, Brodeur RR, Hallgren RC. Chronic neck pain, standing balance, and suboccipital muscle atrophy - a pilot study. J Manipulative Physiol Ther. 1997;20(1):24-29.

58. Passias PG, Segreto FA, Bortz CA, Horn SR, Frangella NJ, Diebo BG, Hockley A, et al. Fatty infiltration of cervical spine extensor musculature: is there a relationship with cervical sagittal balance? Clin Spine Surg. 2018;31(10):428-434.

59. Passias PG, Segreto FA, Horn SR, Lafage V, Lafage R, Smith JS, Naessig S, et al. Fatty infiltration of the cervical extensor musculature, cervical sagittal balance, and clinical outcomes: An analysis of operative adult cervical deformity patients. J Clin Neurosci. 2020;72:134-141.

60. Riew KD, Raich AL, Dettori JR, Heller JG. Neck Pain Following Cervical Laminoplasty: Does Preservation of the C2 Muscle Attachments and/or C7 Matter? Evid Based Spine Care J. 2013;4(1):42-53.

61. Agyei JO, Smolar DE, Hartke J, Fanous AA, Gibbons KJ. Cervical kyphotic deformity worsening after extensor 
cervical muscle paralysis from botulinum toxin injection. World Neurosurg. 2019;125:409-413.

62. Ahdab R, Creange A, Benaderette S, Lefaucheur JP. Cervical spondylotic amyotrophy presenting as dropped head syndrome. Clin Neurol Neurosurg. 2009;111(10):874-876.

63. Tamai K, Grisdela P, Jr., Romanu J, Paholpak P, Nakamura $\mathrm{H}$, Wang JC, Buser Z. The impact of cervical spinal muscle degeneration on cervical sagittal balance and spinal degenerative disorders. Clin Spine Surg. 2019;32(4):E206-E213.

64. Alpayci M, Ilter S. Isometric Exercise for the Cervical Extensors Can Help Restore Physiological Lordosis and Reduce Neck Pain: A Randomized Controlled Trial. Am J Phys Med Rehabil. 2017;96(9):621-626.

65. Chung S, Jeong YG. Effects of the craniocervical flexion and isometric neck exercise compared in patients with chronic neck pain: A randomized controlled trial. Physi- other Theory Pract. 2018;34(12):916-925.

66. Mayoux-Benhamou MA, Revel M, Vallee C, Roudier R, Barbet JP, Bargy F. Longus colli has a postural function on cervical curvature. Surg Radiol Anat. 1994;16(4):367371.

67. Mitsutake T, Sakamoto M, Chyuda Y, Oka S, Hirata H, Matsuo T, Oishi T, et al. Greater cervical muscle fat infiltration evaluated by magnetic resonance imaging is associated with poor postural stability in patients with cervical Spondylotic radiculopathy. Spine (Phila Pa 1976). 2016;41(1):E8-14.

68. Inoue $\mathrm{H}$, Montgomery S, Aghdasi B, Tan Y, Tian H, Jian $\mathrm{X}$, Terrell R, et al. Analysis of relationship between paraspinal muscle fatty degeneration and cervical spine motion using kinetic magnetic resonance imaging. Global Spine J. 2012;2(1):33-38. 